\title{
AS TECNOLOGIAS DA INFORMAÇÃO E COMUNICAÇÃO NO APRIMORAMENTO DO PROCESSO LEGISLATIVO: FUNDAMENTOS PARA UM PROCESSO LEGISLATIVO MAIS INTERATIVO
}

\author{
INFORMATION AND COMMUNICATION TECHNOLOGIES IN THE \\ IMPROVEMENT OF THE LEGISLATIVE PROCESS: MAIN LINES FOR A \\ LEGISLATIVE PROCESS MORE INTERACTIVE
}

\author{
'João Victor Rozatti Longhi \\ ${ }^{2}$ Rubens Beçak
}

\section{RESUMO}

As Tecnologias da Informação e Comunicação (TICs) transformaram definitivamente a sociedade contemporânea. São muitas os comportamentos que se alteraram por força do uso maciço de tais tecnologias chegando às instituições públicas e privadas e ao Direito como um todo. Na formação da vontade política, por seu turno, as TICs têm exercido papel cada vez mais relevante. Este trabalho tem por objetivo central demonstrar que a interseção entre tecnologia e deliberação política é uma realidade possível no Brasil. Para tal, primeiramente, analisa brevemente estudo de duas destas experiências, consagradas em vários estudos por seu pioneirismo. A primeira diz respeito à realidade estoniana do voto eletrônico online. A segunda é a experiência islandesa de 2011 , conhecida pelo alto grau de interatividade e colaboratividade durante o processo. Finalmente, na segunda parte, busca-se através de uma incursão sobre os modelos de democracia averiguar se o Brasil está preparado para prosseguir na evolução de seu modelo democrático rumo a um maior grau de participação. E a hipótese principal é a de que a interatividade pode se tornar regra através do processo legislativo.

Palavras-chave: Democracia, Internet, Processo legislativo, Estônia, Islândia, E-democracia

\begin{abstract}
Information and Communication Technologies (ICTs) definitely transformed contemporary society. There are many behaviors that have changed under the massive use of such technologies, coming to public and private institutions and the law as a whole. In the formation of political will, in turn, ICTs have played increasingly important role. This work has as main objective to study the possibility of making true the intersection between technology and policy deliberation is a possible reality in Brazil. To do this, first, briefly reviews the study of two of these experiences, enshrined in several studies for its pioneering. The first concerns the Estonian reality of online electronic voting. The second is the Icelandic experience in 2011, known by the high degree of interactivity and colaborativity during the process. Finally, in the second part, we seek through a raid on democracy models see if Brazil is prepared to continue the evolution of its democratic model towards a greater degree of participation. And the main hypothesis is that interactivity can become rule through the legislative process.
\end{abstract}

Keywords: Democracy, Internet, Legislative process, Estonia, Iceland, E-democracy

\footnotetext{
${ }^{1}$ Doutorando em Direito pela Universidade de São Paulo - USP, São Paulo, (Brasil). Professor Assistente II de Direito da Universidade Federal de Uberlândia - UFU, Minas Gerais. E-mail: joaovrlonghi@ yahoo.com.br ${ }^{2}$ Doutor em Direito pela Universidade de São Paulo -USP, Ribeirão Preto, (Brasil). Professor Associado da Universidade de São Paulo-USP, na Faculdade de Direito de Ribeirão Preto. E-mail: rubens.becak@ gmail.com
} 


\section{INTRODUÇÃO}

O uso maciço das Tecnologias da Informação e Comunicação (TICs) é um fator decisivo para inúmeras mudanças de comportamento ao longo da história recente. Por força destas e outras tecnologias semelhantes, indivíduos e instituições públicas e privadas tem cada dia mais se rendido às novas práticas.

E o Direito não é diferente. No que concerne especificamente ao Direito Constitucional, pontos sensíveis como Direitos Fundamentais, Regulação da administração pública, dentre outros, é instado a se adaptar ante aos novos desafios de proteção da pessoa humana e adaptação às demandas de construção de um governo eletrônico (e-government).

Igualmente, outro ponto nevrálgico que desperta interesses científicos em Direito Constitucional, Ciência Política e outras ciências sociais, diz respeito à intersecção entre exercício da soberania popular e recurso à tecnologia.

E é neste ponto que se insere este o objetivo geral deste trabalho, que tem por meta principal averiguar em que medida o Brasil pode aprender com a experiência estrangeira para enriquecer a, em alguns quesitos, já pioneira estrutura nacional de e-democracia.

Desta maneira, busca atingir dois objetivos específicos. Primeiramente, analisará brevemente duas destas experiências estrangeiras, tidas como pioneiras na história recente. Tratase do voto eletrônico online (Internet Voting) na Estônia e a tentativa de reforma constitucional de 2011 na Islândia (para alguns uma genuína Constituinte), conhecida pelo alto grau de interatividade e colaboração por meio das redes sociais durante todo o processo.

Posteriormente, na segunda parte, visa-se, por meio de uma breve análise de tipologias de modelos de democracia e outros conceitos, verificar em que medida o Brasil está preparado para prosseguir na evolução do modelo democrático, promovendo maior participação por meio das TICS. E a hipótese principal é a de que a interatividade pode se tornar regra através do veículo tradicional de busca da síntese das controvérsias políticas: a lei. Ou seja, busca-se dissertar sobre a possibilidade de que, no Brasil, haja fundamentos para um processo legislative mais interativo.

A método adotado será o hipotético-dedutivo, partindo-se da hipótese de que o atual sistema democrático brasileiro estaria sim pronto para aprender com a experiência estrangeira e 
aprimorar o seu modelo democrático em prol de maior participação, especialmente através do recurso à interatividade pelas TICs durante o processo legislativo. $\mathrm{O}$ instrumental metodológico adotado será o da pesquisa teórica majoritariamente bibliográfica com recurso também à análise documental jurisprudencial.

\section{EXPERIÊNCIAS ESTRANGEIRAS DE E-DEMOCRACIA}

Sabe-se de muitas experiências que mesclam tecnologia e soberania popular ao longo da história recente. Entretanto, serão analisadas brevemente duas delas, por seu pioneirismo e relevância no cenário constitucional contemporânea. Trata-se do voto eletrônico na Estônia e da tentativa de reforma colaborativa da Constituição Islandesa de 2011.

\subsection{O $e$-Voting na Estônia}

São vários exemplos de recurso à tecnologia no processo eleitoral na Europa, nos Estados Unidos e mesmo no Brasil. Analisando a realidade norte-americana, Michael R. Alvarez e Trad E. Hall asseveram que o fenômeno não é exclusividade das Tecnologias da Informação e Comunicação contemporâneas. Formulários integrados de papel e outros artefatos foram e são utilizados para racionalizar o uso do processamento de dados e da informática na compilação dos resultados eleitorais.

${ }^{1}$ Cf. ALVAREZ, Michael R.; HALL, Trad E. Eletronic Elections: the perils and promises of digital democracy. Revista de Direito, Governança e Novas Tecnologias | e-ISSN: 2526-0049 | Minas Gerais | v. 1 | n. 2 | p. 120 - 139 | Jul/Dez 2015. 
Por essa razão, definem voto eletrônico como qualquer dispositivo de votação em que as preferências dos eleitores são computadas, transformadas em dados e processadas automaticamente. Assim, o conceito é amplo, podendo ser utilizado seja quando ocorre através de dispositivos mecânicos que registram o voto no objeto de votação eletrônica (chamado registro eletrônico direto), seja usando qualquer outro método para registrar o voto. Ou seja, o elemento central está no fato de que, ao utilizar tecnologias de votação eletrônica, o eleitor interage com um sistema computadorizado que traduz a opção do eleitor eletronicamente, o qual é de alguma forma gravado e preservado para computação posterior.

Logo, a urna eletrônica pode simplesmente gravar o voto em algum dispositivo de armazenamento eletrônico padrão ou um conjunto de dispositivos (envolvendo mídia não removível ou removível), como também pode traduzi-la em uma cédula de papel ou outro material que é impressa ao eleitor para verificação e posterior depósito na urna tradicional. ${ }^{2}$

Dessa maneira, ainda segundo os Alvarez e Hall, há duas modalidades de voto eletrônico: os que ocorrem em redes fechadas e aqueles que ocorrem em redes abertas, a que denominam "Voto pela Internet (Internet voting)." 3

\footnotetext{
Princeton: Princeton University Press, 2008. p. 8 e ss.

${ }^{2}$ Convém menção à lição dos autores no original: "In our definition, an electronic voting device is one which the voter inputs preferences electronically - either flipping some mechanical levers that record a vote into the electronic voting device (the so-called direct record electronic device), tapping selections on a "touch screen" voting system, or using some other input method to indicate a vote to an electronic voting device. When using electronic voting technologies, the voter is interacting with a computerized system that translates the voter's input into an electronic stream of information that is then somehow recorded and preserved for later tabulation. The electronic voting machine might simply record the voter's input into some type electronic storage device or devices (involving nonremovable or removable media), it might translate the voter's input onto a paper ballot that is printed for the voter to verify and deposit in a ballot box, or it might store that is printed for the voter to verify and deposit in a ballot box or it might store the voter's input electronically and provide a printed ballot that the voter can verify. As long as the voter's preferences are being recorded, by the voter, into some initial stream of electronic information, we consider that to be electronic voting. Later, in some places where the details are relevant to our discussion, we sometimes differentiate between different typos of electronic voting machines." ALVAREZ, Michael R.; HALL, Trad E. Eletronic Elections: the perils and promises of digital democracy. Princeton: Princeton University Press, 2008. p. 9-10.

${ }^{3}$ Convém menção à lição dos autores no original: "The electronic voting device can stand by itself, be networked to other voting devices in a precinct or early voting station (local-area network [LAN]), or be attached to a widearea network ([WAN], like the Internet). In present discussion, we maintain the distinction between WAN electronic voting, which we will call "Internet voting") and which we have discussed in our 204 book on the topic), and stand-alone and LAN electronic voting. The distinction follows the typical parameters of public debate about WAN versus non-WAN electronic voting." ALVAREZ, Michael R.; HALL, Trad E. Eletronic Elections: the
} 
Explica Maria Augusta Ferreira da Silva Castanho, que uma delas já é adotada pelo Brasil em período eleitoral. Porém, pelo sistema brasileiro de urna eletrônica, o cidadão precisa se dirigir à zona eleitoral para efetivar o voto, que não entrega comprovante impresso, ${ }^{4}$ tratando-se de um "voto eletrônico off-line", 5 o qual se concretiza na rede fechada que interliga as urnas à base de dados do Tribunal Superior Eleitoral após o cômputo da votação.

O sistema brasileiro de urna eletrônica, embora seja elogiado por muitos por ser avançado e apresentar níveis consideráveis de segurança, parece representar que apenas parte do caminho ruma à interação entre Tecnologias da Informação e Comunicação e participação popular tenha sido percorrido no país. Especialmente pelo fato de o sistema ainda ser parte de um processo em que o voto eletrônico é "off-line" não representando o que Alvarez e Hall denominam de "voto pela Internet."

Razão pela qual é necessária a análise de sistemas mais interativos de votação eletrônica para a proposição de formas de aprimoramento da e-democracia no sistema brasileiro. E a Estônia, neste ponto, assume papel relevante.

Salienta Maria Augusta Ferreira da Silva Castanho que naquele país o voto adotado nas eleições regulares é a modalidade de voto eletrônico online, remoto, ou à distância. Ou seja, possibilita ao cidadão votar a partir de seu próprio dispositivo, sem deixar de observar as regras básicas do sufrágio. Logo, o voto se mantém secreto, individual, restrito ao período oficial

perils and promises of digital democracy. Princeton: Princeton University Press, 2008. p. 9-10.

${ }^{4}$ Inclusive, Nesse sentido, o STF apreciou a constitucionalidade de projeto de lei que visava determinar a entrega de comprovante de votação impresso ao eleitor após o voto. O dispositivo foi declarado inconstitucional, principalmente, por afronta, dentre outros fundamentos, ao mandamento constitucional de impessoalidade do voto: "Ementa: Constitucional. Eleitoral. Art. 5. ${ }^{\circ}$ da Lei 12.034/2009: impressão de voto. Plausibilidade jurídica dos fundamentos postos na ação. Sigilo do voto: direito fundamental do cidadão. Vulneração possível da urna com o sistema de impressão do voto: inconsistências provocadas no sistema e nas garantias dos cidadãos. Inconstitucionalidade da norma. Cautelar deferida. 1. A exigência legal do voto impresso no processo de votação, contendo número de identificação associado à assinatura digital do eleitor, vulnera o segredo do voto, garantia constitucional expressa. 2. A garantia da inviolabilidade do voto põe a necessidade de se garantir ser impessoal o voto para garantia da liberdade de manifestação, evitando-se qualquer forma de coação sobre o eleitor. 3. A manutenção da urna em aberto põe em risco a segurança do sistema, possibilitando fraudes, impossíveis no atual sistema, o qual se harmoniza com as normas constitucionais de garantia do eleitor. 4. Cautelar deferida para suspender a eficácia do art. 5. ${ }^{\circ}$ da Lei 12.034/2002. (STF - MC na ADIn 4.543/DF - Sessão Plenária - j. 19.10.2011 - v.u. - rel. Min. Cármen Lúcia - DJe 02.03.2012)

${ }^{5}$ Cf. CASTANHO, Maria Augusta Ferreira da Silva. O processo eleitoral. (TESE) São Paulo: Universidade de São Paulo, 2014. Orientador(a): Mônica Hermann Salem Caggiano. p. 295.

determinado para o sufrágio nacional. ${ }^{6}$ 
Assim, destaca que, internacionalmente, a Estônia é observada por diversos países e organismos internacionais, já que é o único país do mundo que adota a possibilidade de votação nacional pela Internet. ${ }^{7}$ Por sua vez, no plano interno, além de receber apoio da população, o modelo é tido como seguro e independente de forças governamentais por parte dos partidos políticos. ${ }^{8} \mathrm{Na}$ opinião da autora, “ o valor desse modelo está na sua capacidade de transmissão abundante de informações políticas mais precisas, mais fáceis de serem acessadas, mais inclusivas, de modo que ele não deve ser desprezado como solução possível e viável ao incremento da motivação política." 9

Aprofundando-se na análise do sistema estoniano, Michael R. Alvarez, Trad E. Hall e Alexander Trechsel ressaltam os fatores que levaram a consagração do voto eletrônico pela Internet na Estônia: acesso quase total à Internet, regulamentação desenvolvida do Internet voting, sistema criptografado único de identificação digital do eleitor e confiança no sistema por parte da população. ${ }^{10}$

Porém, embora o sistema estoniano tenha o mérito de trazer a possibilidade de se utilizar como regra o Internet voting, deve-se frisar que o modelo democrático em que está inserido em nada difere do tradicional. Ou seja, o sistema de voto eletrônico remoto pode ser usado para trazer maior comodidade ao cidadão, mas não necessariamente mais participação. Razão pela qual a experiência posteriormente analisada enriquecerá o debate.

${ }^{6}$ Cf. Idem. p. 297.

${ }^{7}$ Cf. Id. p. 299

${ }^{8}$ Cf. Id. p. 298.

${ }^{9}$ Id. p. 302.

${ }^{10}$ ALVAREZ, R.; HALL, T.; TRECHSEL A. Internet Voting in Comparative Perspective: The Case of Estonia. Political Science and Politics. Cambridge: Cambridge University Press, v. 42, p. 497-505, 2009. 


\subsection{O Projeto de Constituição Islandesa de 2011 (“constituição.com”)}

Outra experiência amiúde analisada por juristas, politólogos, etc. é a do projeto de Constituição Islandesa de 2011, o que Uadi Lâmego Bulos denomina de "constituição.com" (crowdsourcing): "aquela cujo projeto conta com a opinião maciça dos usuários da internet, que, por meio de sites de relacionamento [redes sociais], externam seu pensamento a respeito dos temas a serem constitucionalizados."11

Bulos elenca alguns fatores que possivelmente teriam levado a Islândia a ser pioneira nesta iniciativa: a população do país é pequena, cerca de 310 mil habitantes; o elevado nível educacional, que facilita a compreensão da estrutura do crowdsourcing, elaboração colaborativa de projetos com ajuda de internautas; o amplo acesso à Internet (quase total, de $97 \%$ da população, sendo que $64,8 \%$ acessam o Facebook). ${ }^{12}$

Embora reconheça que o tema gerou controvérsias, inclusive entre o povo islandês, ${ }^{13}$ assevera que o cerne da questão diz respeito ao às discussões em torno do uso de sites no processo constituinte. E, em sua opinião, “ as vantagens da constituição.com são tremendas e indiscutíveis", tais como o aumento da participação popular; a popularização do acesso do povo ao processo constituinte; a maior possibilidade de a Constituição refletir a visão da maioria e não certos grupos de interesse; além do respeito ao princípio da transparência, e da

\footnotetext{
${ }^{11}$ BULOS, Uadi Lâmego. Curso de direito constitucional. 8. ed. rev. e atual. 11. de acordo com a E.C. n. $76 / 2013$. São Paulo: Saraiva, 2014. p. 112.

${ }^{12}$ BULOS, Uadi Lâmego. Curso de direito constitucional. 8. ed. rev. e atual. 11. de acordo com a E.C. n. 76/2013. São Paulo: Saraiva, 2014. p. 112. Continua o autor: "Isso facilitou, sobremaneira, a discussão de várias propostas, dentre as quais a publicidade dos documentos governamentais, a definição das permissões de uso dos recursos naturais, a mudança do semipresidencialismo pelo parlamentarismo, a revisão do status de religião estatal, conferido à igreja evangélica luterana e a recuperação de propriedades roubadas. Assim, as reuniões da Assembleia Constituinte foram transmitidas online, permitindo aos internautas opinarem a respeito da nova Constituição islandesa. Tais opiniões foram convertidas em um rascunho constitucional, entregue ao Parlamento em 29 de julho de 2011.” Idem. p. 112.

13 "Para uns, a internet não ajuda a democracia. O que os governos deveriam fazer é vigiar os cidadãos, identificar e prender dissidentes, em vez de permitir o uso da web para se debater o próprio ato de feitura das constituições. Outros, numa linha mais avançada e condizente com a realidade de nosso tempo, acreditam que a internet amplia
} 
os canais democráticos, pluralizando o debate constitucional, mediante a consagração de ferramentas cotidianas, como o Facebook, o Twitter e o YouTube." Id. p. 112. liberdade de expressão, sem censura ou limites. ${ }^{14}$

Embora o tom otimista da análise de Bulos, saliente-se que o projeto de Constituição Islandês de 2011 não chegou a ser aprovado e veio a se tornar norma através do processo originalmente concebido.

Em estudo mais detida do tema, Helène Landemore descreve com maior profundidade o processo colaborativo de deliberação sobre os principais pontos de Constituição islandesa. Primeiramente, narra que, após sentir duramente os efeitos da crise financeira de 2008, o povo islandês clamava por mais participação na decisões políticas.

Em meados de 2009, inicia-se um movimento (denominado "The Antihill") em que aproximadamente 1500 pessoas foram convocadas para um encontro nacional onde pretendiam discutir o "futuro da Islândia". Os resultados do evento ganharam a media e a esfera pública em geral rapidamente. E alterar o texto da Constituição foi apontado como uma das principais metas.

Em junho de 2010, o Parlamento aprova o início do processo de reforma constitucional, nomeando-se um Comitê Constitucional. Em novembro do mesmo ano, foi organizado um segundo evento, conhecido por "Fórum Nacional 2010", em cooperação entre Legislativo e os organizadores do fórum anterior (The Antihill). Este procurou estabelecer os principais pontos de vista sore a organização do Estado e da Constituição com a pretensão de que se elaborasse uma espécie de pré-projeto de Constituição.

Entretanto, em 2011, a Suprema Corte do país anulou a primeira assembleia por falhas procedimentais. Mas o Parlamento (“Altinghi”) optou por nomear os 25 membros eleitos como parte do "Conselho Constitucional", dando prosseguimento ao processo. ${ }^{15}$ Após a composição

\footnotetext{
${ }^{14}$ Cf. BULOS, Uadi Lâmego. Curso de direito constitucional. 8. ed. rev. e atual. 11. de acordo com a E.C. n. 76/2013. São Paulo: Saraiva, 2014. p. 113. Ao final, o autor deposita as esperanças no portal e-democracia da câmara, o que parece ser apenas um exemplo do que ele acredita ser o potencial da Internet no aprimoramento do processo de deliberação democrática: "No Brasil, esperamos que essa concepção, um dia, se materialize em toda a sua plenitude, valendo destacar o portal e-Democracia, que, de certo modo, é um prenúncio neste sentido (http://edemocracia.camara.gov.br).” Idem. p. 112.

${ }^{15}$ Cf. LANDEMORE, Helène. Inclusive Constitution-Making: the Icelandic Experiment. No prelo. p. 5 . Disponível em: https://www.academia.edu/5289629/Inclusive_Constitution-Making_the_Icelandic_Experiment.
} 
do Conselho, o plano era apresentar um projeto em três meses, com a possibilidade de uma extensão de um mês. O projeto foi apresentado dentro do prazo de 4 meses.

Os membros deste Conselho, frise-se composto por pessoas comuns do povo, porém delegados eleitos para constituir o elo popular dentro do que seria uma Assembleia Constituinte, passaram a postar o resultado das reuniões para colher a opinião e eventuais sugestões de usuários no Facebook. ${ }^{16} \mathrm{O}$ que garantiu maior interatividade com os cidadãos para que contribuíssem com o projeto. Eis um organograma apresentado pela autora que representa todo o processo: ${ }^{17}$

Acesso em 10 ago. 2015.

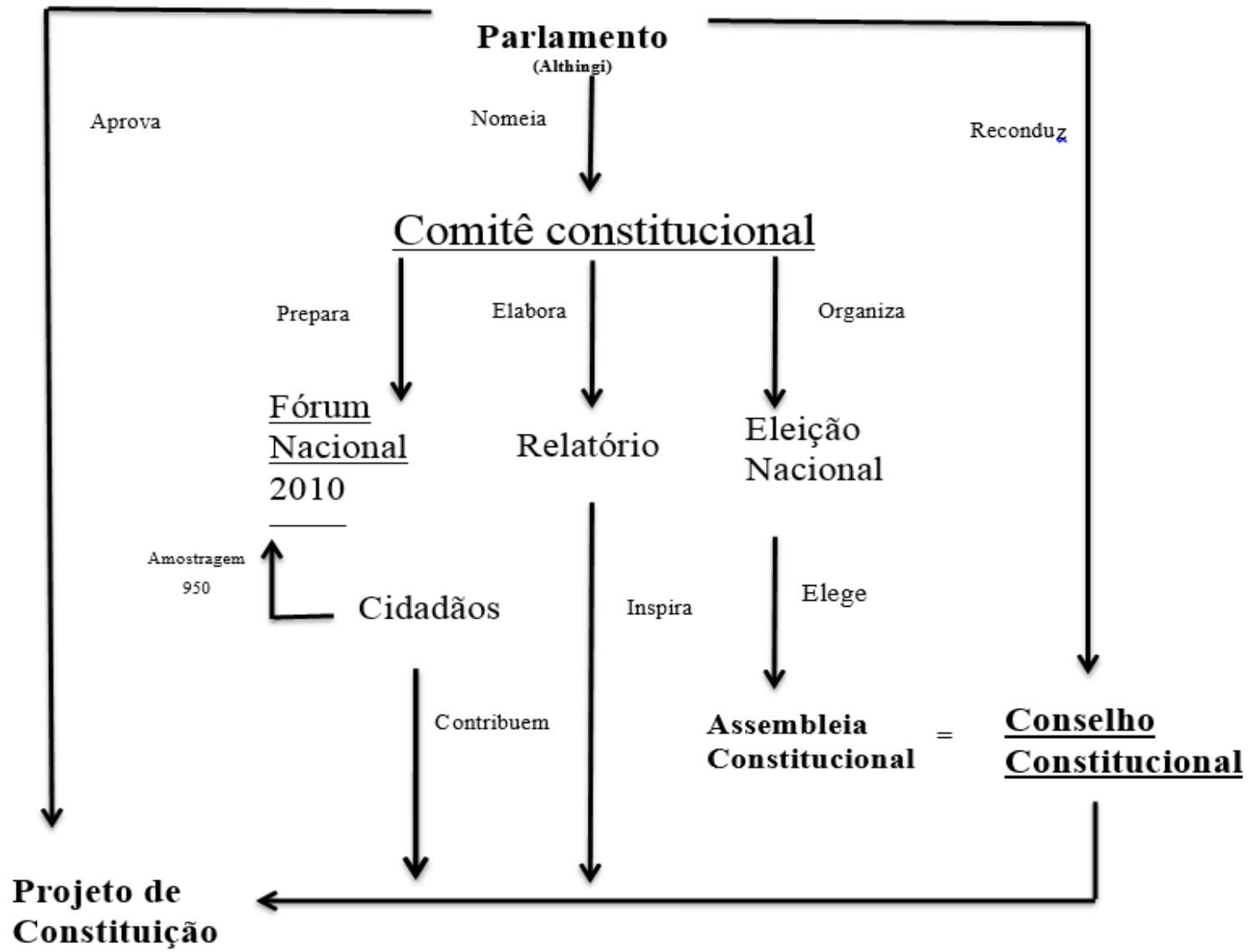

\footnotetext{
${ }^{16}$ Convém menção ao original: "The ideas of wisdom of the crowds and the collective intelligence of regular citizens have thus been slowly gaining ground. Among the boldest implementations, Iceland's recent experiment of crowdsourcing the very writing of its new constitution is worth mentioning. Following the institutional crisis that resulted from the massive financial and economic meltdown of 2008, Iceland has, indeed, embarked on a major overhaul of its foundational text. As of July 2011, regular Icelanders have thus been invited to contribute ideas via the Internet and social media platforms such as Facebook, Twitter, YouTube, and Flickr, to supplement the work of a constitutional council, which regularly posts drafts on the Internet. ${ }^{11}$ Whether these experiments are successful or not and whatever their flaws, they reflect the fact that the idea of collective intelligence has become mainstream and speak to its appeal, particularly in times of crisis." LANDEMORE, Helène. Democratic reason : politics, collective intelligence, and the rule of the many. Princeton: Princeton University Press, 2013. p. 23.
}

17 KOK, Alexander. Icelandic National Forum 2010. 2011. Participedia. Disponível em: http://participedia.net/en/cases/icelandic-national-forum-2010. Acesso em: 10 ago. 2015. Tradução livre. 
Após discussões e votações, em 2012, o projeto foi submetido a referendo não- vinculante ao Parlamento. Com participação de 235 mil eleitores (lembrando que a população islandesa é de pouco mais de 300 mil habitantes), o projeto foi aprovado por mais de 2/3, provendo de legitimidade a nova constituição. que orientou a produção do projeto final ${ }^{18}$.

Contudo, em 2012, o Parlamento rejeitou o, embora bem intencionado, o projeto de Constituição islandesa em formato crowdsourcing. Segundo Landemore, as razões deste naufrágio podem ser de diversas ordens. Afinal, alguns culpam o povo islandês que, uma vez passado o pior da crise econômica, enfraqueceu o movimento em torno do projeto da reforma constitucional, já que não seria mais visto como necessário ou urgente. Outros, a oposição, já que que partidos, políticos, ou mesmo acadêmicos sentiam-se ameaçados pela perspectiva de mudança ou estariam frustrados por não terem o controle sobre o projeto, bem como a hostilidade de poderosos interesses econômicos acerca de dispositivos específicos do texto.

Outras explicações talvez podem ser encontradas, incluindo a ambição posterior ao início dos trabalhos de se reescrever a Constituição em sua totalidade ao invés de meramente alterar alguns artigos. ${ }^{19}$

Ao final, os islandeses teria que votar em um segundo referendo não vinculativo ou não adotar a nova Constituição colaborativa em 2013, ao mesmo tempo que as eleições parlamentares seriam realizadas. O recém-eleito Parlamento ainda teria de aprovar a nova Constituição. O que não aconteceu. ${ }^{20}$

Não obstante, por outro lado, a autora destaca os pontos positivos da experiência islandesa: 1. abertura do processo a participação popular; 2. representação relativamente abragente dos setores da sociedade islandesa por meio dos delegados, em que a participação direta não era uma opção; 3. transparência na maioria dos procedimentos. ${ }^{21}$

E, conforme acentua, na parte mais interativa, até estrangeiros poderiam participar do processo. Tudo se valendo da interação constante por meio das redes sociais. ${ }^{22}$ Portanto, embora ainda em grande medida utópico (e de resultado frustrante), o processo de reforma constitucional islandês serve para comprovar que um procedimento legislativo ou constituinte

\footnotetext{
18 Cf. LANDEMORE, Helène. Inclusive Constitution-Making: the Icelandic Experiment. No prelo. p. 6. Disponível em: https://www.academia.edu/5289629/Inclusive_Constitution-Making_the_Icelandic_Experiment. Acesso em 10 ago. 2015.

19 Afirma-se, por exemplo, que o lobby dos pescadores lutou nos bastidores pela derrocada do dispositivo que previa que recursos naturais seriam declarados como bens públicos e, portanto, não estariam mais disponíveis aos particulares uma grande fonte de enriquecimento para eles no início dos anos 1990. Cf. LANDEMORE, Helène. Inclusive Constitution-Making: the Icelandic Experiment. No prelo. p. 6. Disponível em: https://www.academia.edu/5289629/Inclusive_Constitution-Making_the_Icelandic_Experiment. Acesso em: 10 ago. 2015.

20 https://www.academia.edu/5289629/Inclusive_Constitution-Making_the_Icelandic_Experiment. Acesso em 10 ago. 2015.

21 Cf. LANDEMORE, Helène. Inclusive Constitution-Making: the Icelandic Experiment. No prelo. p. 8. Disponível em: https://www.academia.edu/5289629/Inclusive_Constitution-Making_the_Icelandic_Experiment. Acesso em 10 ago. 2015.

22 Cf. Idem. p. 6.
} 
mais interativo é possível. Ainda que, em algum momento, poderá trazer tensões com as estruturas anacrônicas da democracia representativa ainda presentes e (muito) resistentes a um modelo com maior participatividade.

Entrave que, após a análise da realidade brasileira contemporânea, poderá ter uma proposta de alternativa.

\section{O MODELO DEMOCRÁTICO BRASILEIRO NA ATUALIDADE COMO UM TERRENO FÉRTIL PARA PROMOÇÃO DE MAIOR DELIBERAÇÃO}

Deliberação e interatividade são conceitos que se entrelaçam no âmbito contemporâneo das Tecnologias da Informação e Comunicação. Mas a noção de democracia deliberativa é muito maior e anterior ao uso maciço das TICS.

Preliminarmente, deve-se saber que há inúmeras tipologias que pretendem estabelecer modelos de democracia de acordo com o maior ou menor grau de participação dos cidadãos no processo de tomada de decisão política. ${ }^{23}$

Uma interessante tipologia, de caráter não estanque mas abrangente, é a de Leonardo Morlino. O autor analisa os processos de democratização em várias transições. Inicialmente, são cinco os movimentos que interessam: 1. da democracia aos diversos tipos de autoritarismos; 2. de regimes não democráticos a regimes democráticos; 3. de um tipo de democracia a outro; 4. de uma democracia real de baixa qualidade a uma de maior qualidade; 5. de um tipo de democracia nacional a um supranacional. ${ }^{24}$

\footnotetext{
${ }^{23}$ Por exemplo, Democracias de Assembleia, representativas e de monitoramento, sugeridas por John Keane. Cf. KEANE, John. The life and death of Democracy. New York: Simon \& Schuster, 2009. P. 17 e ss. Outras tipologias que carecem citação são as de Arendt Lipjhardt. Cf. LIJPHART, Arend. Patterns of democracy. New Heaven: Yale University Press, 1999. Passim.

${ }^{24}$ Cf. MORLINO, Leonardo. Democracias y democratizaciones. Trad. Cesar Cansino y Israel Covarrubias. CEPCOM: Mexico, 2005. p. 33
} 
Atendo-se à parte que mais interessa ao regime brasileiro, é possível asseverar que, com a Carta Magna de 1988, pode-se considerar ultrapassado o autoritarismo (desconsiderando-se os discursos em prol de um eventual retrocesso), concentrando-se a análise nos processos de aprimoramento do regime democrático atual. Ou seja, de melhoria de sua qualidade, para se passar a dissertar de um modelo democrático diverso, mais participativo.

Ao analisar os conceitos de democracia na contemporaneidade, Morlino elenca os seguintes: geral, procedimental, genética, mínima e normativa. ${ }^{25}$ Ao partir da análise de Robert Dahl, ${ }^{26}$ Giovanni Sartori, , dentre outros, conclui o autor que todas elas representam modelos simplistas, mas que servem como supedâneo inicial à análise dos modelos de democracia.

Assim, posteriormente, apresenta uma tipologia que mescla dois critérios: regime de governo e sistema eleitoral. Desta maneira, propõe a seguinte classificação: a. presidencialismo e sistema eleitoral majoritário; Semipresidencialismo e sistema eleitoral majoritário, semipresidencialismo e sistema eleitoral proporcional; semipresidencialismo e sistema eleitoral proporcional reforçado ou majoritário; parlamentarismo e sistema eleitoral proporcional ; presidencialismo e sistema eleitoral proporcional. ${ }^{27}$ Ao final, assevera que estes critérios também ajudam mas não exaurem a mensuração da qualidade da democracia.

Outro conjunto de características, segundo o autor, que influi na qualidade da democracia diz respeito ao sistema de partidos. A partir do grau de competitividade produzido pelos sistemas partidários, apresenta a seguinte tipologia: Partido predominante coeso com um líder forte e governos monopartidaristas; bipartidarismo e governos monopartidaristas; multipartidarismo homogêneo e governos de coalizão; multipartidarismo heterogêneo e governos de coalizão. ${ }^{28}$

Não obstante, um quarto elemento vem à tona no que concerne ao grau de autonomia da

\footnotetext{
${ }^{25}$ Cf. Idem. p. 48.

${ }^{26}$ V. por todos, DAHL, Robert. A. A democracia e seus críticos. Trad. Patrícia de Freitas Ribeiro; rev. de trad. Aníbal Mari. São Paulo: WMF Martins Fontes, 2012. passim.

${ }^{27}$ Cf. MORLINO, Leonardo. Cit. p. 50

${ }^{28}$ Cf. Idem. p. 52. Segundo o autor, esta tipologia se inspira em Giovanni Sartori. V. por todos, SARTORI, Giovanni. Política y método en las ciencias sociales. Mexico: Fondo de Cultura económica, 1995. passim.
} 
sociedade civil em relação às instituições anteriores (partidos, governo, Parlamento). Segundo estas, são quatro os sistemas possíveis: Autonomia, semiautonomia; semicontrole, controle ${ }^{29}$

Postos os critérios, Morlino passa a analisar o que denomina de modelos empíricos de democracia, ou seja, aqueles, após uma aproximação pragmática, encaixam-se ou não nos critérios supramencionados. São cinco os tipos propostos: majoritária; plebiscitaria; debilmente majoritária, proporcional e conflitual. Mesclando-os, propõe a seguinte taxonomia: I. Majoritária (com: presidencialismo e sistema eleitoral majoritário ou semipresidencialismo e sistema eleitoral proporcional reforçado ou majoritário; bipartidarismo e governos monopartidaristas; Autonomia); II. Plebiscitária (com: presidencialismo e sistema eleitoral majoritário ou semipresidencialismo e sistema eleitoral majoritário ou semiparlamentarismo e sistema eleitoral proporcional reforçado ou majoritário; partido predominantemente coeso, com um lider forte e governos monopartidaristas; controle ou semicontrole); III. Democracia fortemente majoritária (com: presidencialismo e sistema eleitoral majoritário ou semipresidencialismo e sistema eleitoral majoritário ou semiparlamentarismo e sistema eleitoral reforçado ou majoritário; Partido predominantemente coeso, com um líder forte e governos monopartidaristas ou multipartidarismo; homogêneo e governos de coalisão; controle); IV. Democracia debilmente majoritária (com: semipresidencialismo e sistema eleitoral proporcional ou semiparlamentarismo e sistema eleitoral fechado ou majoritário ou presidencialismo e sistema eleitoral proporcional; partido predominantemente coeso, com um líder forte e governos monopartidaristas; Semiautonomia ou semicontrole); V. Proporcional (semiparlamentarismo e sistema eleitoral proporcional reforçado ou majoritário ou parlamentarismo e sistema eleitoral proporcional; Multipartidarismo homogêneo e governos de coalisão; Autonomia ou semiautonomia); VI. Conflitual (com semipresidencialismo e sistema eleitoral proporcional reforçado ou majoritário ou presidencialismo e sistema eleitoral proporcional. multipartidarismo heterogêneo e governos de coalizão, semicontrole ou controle). ${ }^{30}$

Não obstante o autor avance na questão da qualificação dos modelos democráticos, o

\footnotetext{
${ }^{29}$ Cf. Idem. p. 54.

${ }^{30}$ Cf. Idem. p. 58.
} 
faz sob uma ótica institucional e macroscópica do ponto de vista estrutural. Não obstante, a questão de como se estruturam determinados Estados democráticos contemporaneamente não uma análise que vai além de uma abordagem descritiva para conceitos mais preceptivos. Eis aí o papel da chamada democracia deliberativa. ${ }^{31}$

Amy Gutmann e Dennis Thompson explicam o conceito asseverando que em uma democracia, líderes devem fundamentar suas decisões e responder racionalmente aos cidadãos. Ou seja, destacam que nem todas as questões, o tempo todo, exigem deliberação. Não obstante, a democracia deliberativa abre espaço para muitas outras formas de tomada de decisão (incluindo a negociação entre grupos e outras operações ordenadas), desde que a utilização destas formas se justifique em algum momento de um processo deliberativo. Sua primeira e mais importante característica, portanto, é sua exigência de fundamentação racional. ${ }^{32}$

Uma das principais justificativas, nos termos dos autores, diz respeito ao fato de que as pessoas não podem ser vistas apenas como objeto da legislação, como sujeitos passivos a serem regulados, mas como agentes anônimos que devem tomar parte do governo e, portanto, de suas decisões. ${ }^{33}$

Os autores ainda elencam duas outras razões pelas quais a democracia deliberativa deve subsistir ao modelo tradicional de democracia representativa. Se o primeiro diz respeito a uma necessidade moral de fundamentação das decisões, os outros dizem respeito, respectivamente, à acessibilidade dos cidadãos ao processo de tomada de decisão. Daí porque as decisões devem

\footnotetext{
${ }^{31}$ Há inúmeros conceitos e estudos acerca da democracia deliberativa. $V$. g., Para uma excelente compilação analisada em recorte histórico evolutivo, V. BEÇAK, Rubens. Democracia: hegemonia e aperfeiçoamento. São Paulo: Saraiva, 2014. Passim.

${ }^{32}$ Cf. GUTMAnN, Amy; THOMPSON, Dennis. Why Deliberative Democracy? Princeton: Princeton University Press, 2009. p. 14. Tradução livre e adaptada. Pela relevância, carece citação do original: "Most fundamentally, deliberative democracy affirms the need to justify decisions made by citizens and their representatives. Both are expected to justify the laws they would impose on one another. In a democracy, leaders should therefore give reasons for their decisions, and respond to the reasons that citizens give in return. But not all issues, all the time, require deliberation. Deliberative democracy makes room for many other forms of decision-making (including bargaining among groups, and secret operations ordered by executives), as long as the use of these forms themselves is justified at some point in a deliberative process. Its first and most important characteristic, then, is its reason-giving requirement."

${ }^{33}$ Cf. Idem. p. 15.
} 
ser tomadas em público e com possibilidade de ampla participação dos cidadãos. ${ }^{34}$

A terceira característica (e talvez mais polêmica), é que no modelo deliberativo proposto as decisões tomadas em conjunto ser vinculante em determinado momento do processo. $\mathrm{O}$ objetivo principal deste elemento diz respeito à necessidade de respeito mútuo às decisões tomadas em conjunto entre representantes e cidadãos. ${ }^{35}$

A implementação dos elementos que compõem o conceito de democracia deliberativa proposto por Gutmann e Thompson, entretanto, traz consigo inúmeros desafios, reconhecidos pelos próprios autores como de duas ordens, teóricas e práticas. Desta forma, salientam que teoricamente, é necessário reconhecer o caráter provisório não só da deliberação democrática, mas também da própria teoria de deliberação democrática, sempre tendente a transformações e aperfeiçoamento. Por seu turno, na prática, a democracia deliberativa carece de poder de resposta. Assim, deve-se trabalhar não só para tornar as instituições familiares da democracia mais amistosas à deliberação, mas também para alargar o âmbito da deliberação às instituições onde anteriormente se ousou ir. ${ }^{36}$

Eis o passo a ser dado com a possibilidade de estabelecimento de um diálogo constante entre instituições e legislativo antes, durante e depois do processo legislativo.

\section{CONCLUSÃO: O DEVIR DE UM PROCESSO LEGISLATIVO MAIS INTERATIVO}

\footnotetext{
${ }^{34}$ Cf. Idem. p. 15-16. Nesse sentido, os autores asseveram que o procedimento difere da proposição de rousseau acerca da privacidade e consciência de cada um na condução do bem comum: "In this respect deliberative democracy stands in contrast to Rousseau's conception of democracy, in which individuals reflect on their own on what is right for the society as a whole, and then come to the assembly and vote in accordance with the general will." Idem. p. 16.

${ }^{35}$ Cf. Idem. p. 25. Nesse sentido, também Ian Shapiro. Cf. SHAPIRO, Ian. The real world of democratic theory. Princeton: Princeton University Press, 2010. p. 147 e ss.

${ }^{36}$ Pela relevância, convém citação no original: "The future of deliberative democracy depends on meeting two general challenges, one theoretical and one practical. Theoretically, deliberative democrats must recognize the provisional nature not only of democratic deliberation but also of their own theory of democratic deliberation. Both their theory and their practice need to be essentially responsive to change. Practically, deliberative democrats must work not only to make the familiar institutions of democracy more friendly to deliberation but also to extend the scope of deliberation to institutions where it has not previously dared to go." Id. p. 85
} 
"A lei escrita, assim, traz consigo, historicamente, a ideia de arbitragem, [...]."

$$
\text { Manoel Gonçalves Ferreira Filho }{ }^{37}
$$

Embora não seja unânime, ${ }^{38}$ Manoel Gonçalves Ferreira Filho identifica duas funções da lei no Estado contemporâneo: arbitragem e promoção do bem-estar geral. Ao passo que a primeira remonta à da lei no Estado moderno, a segunda ganha maior importância no Estado do bem estar social. ${ }^{39}$

Em uma democracia deliberativa, portanto, a norma pode vir a exercer o papel de síntese do processo deliberativo, como expressão mais próxima possível do consenso buscado. E, por seu turno, o processo legislativo assume caráter de centralidade no sistema constitucional, devendo ter sua estrutura repensada de modo a propiciar maior participação antes, durante e depois da criação da regra como forma de mitigar as tensões.

Este parece ser o desafio a ser enfrentado no ambiente contemporâneo, ou seja, fortalecer o papel da norma como elemento de consenso tanto na função arbitral como na promocional de situações jurídicas que carecem de impulsão estatal. Razão pela qual é possível

\footnotetext{
${ }^{37}$ Cf. FERREIRA FILHO, Manoel Gonçalves. Do processo legislativo. 7. ed. rev. e atual. São Paulo: Saraiva, 2012. p. 286.

38 Em outra interessante análise, de um ponto de vista crítico, Bruno Batista da Costa Oliveira traz interessante analise sobre o papel da lei no Estado de Direito brasileiro, e aos interesses a que serve em vários períodos de nossa história: “[...] seja por meio do silêncio legal que convinha apenas à elite agrária no período imperial, da ausência deliberada de regulamentação nos atores do mercado, implementada pelos liberais republicanos, ou ainda, da apropriação, pelo Estado das conquistas sociais, a lei serviu de instrumento para realização das mais variadas vontades, sempre sob o manto da legalidade e do Estado de Direito que lhe conferia legitimidade. [...]" Não obstante conclui, indicando tendência em parte significativa do direito constitucional contemporâneo, que o interesse principal do papel da lei seja o de sintetizar o produto da soberania popular, que pode ser exercida antes, durante e mesmo depois do processo legislativo: "Nosso interesse é a participação popular na feitura dessas leis, mas delimitar o papel por ela exercido em nosso cenário político-social fazia-se de rigor, pois nos auxiliará na compreensão de nosso objeto de estudo. Vale dizer, entender a lei e principalmente o discurso da legalidade que a circunda, ainda que de modo sumário, antes mesmo de compreender o seu procedimento de feitura, porque os dois fenômenos estão intrinsecamente ligados." OLIVEIRA, Bruno Batista da Costa de. A participação popular no processo legislativo: o exercício da cidadania ativa e o discurso do Estado democrático de direito no Brasil. 2010. Dissertação (Mestrado em Direito do Estado) - Faculdade de Direito, Universidade de São Paulo, São Paulo, 2010. p. 59-60.

${ }^{39} \mathrm{O}$ autor se apoia em Jean Mayneaud Cf. FERREIRA FILHO, Manoel Gonçalves. Do processo legislativo. 7. ed. rev. e atual. São Paulo: Saraiva, 2012. p. 280. Ao se referir à lei, o autor trata da norma em sentido lato.
} 
avançar-se usando a ajuda da tecnologia e partindo-se de um ambiente institucional em perspectiva evolutiva em ruptura significativa com as estrutura institucional parece ser o caminho mais viável.

Este trabalho, desta maneira, teve por objetivo lançar o debate acerca de como este processo poderia se viabilizar no Brasil.

Em primeiro lugar, aprendendo-se com a experiência estoniana, que de maneira bem sucedida utilizou-se do voto remoto para a realização das eleições, seria possível inclusive utilizar-se da tecnologia para a realização de outros meios de exercício da soberania popular (como plebiscito, referendo, etc.), além de outras consultas públicas a serem realizadas com segurança.

Além disso, do processo de reforma constituinte islandesa é possível perceber que um outro processo de construção da norma é possível, valendo-se da participação e mobilização populares como forma de promover maior interatividade entre representantes e representados. Sem a necessidade de se negar a existência do Parlamento nem fechar suas portas à opinião popular. Isso com o auxílio da tecnologia que, naquele caso, abriu o debate à participação maciça pela Internet durante grande parte do processo.

Finalmente, voltando-se à análise dos modelos democráticos e, especialmente, do sistema brasileiro, é possível asseverar que, em uma perspectiva histórico-evolutiva, o país está preparado para enfrentar o desafio de promover uma democracia deliberativa, com maior abertura ao debate durante o processo legislativo.

O Marco Civil da Internet, hoje lei $\mathrm{n}^{\mathrm{o}}$ 12.965/14, se mostrou uma experiência valiosa, em que pesem críticas pontuais sobre seu resultado final. Desta maneira, aprender com a experiência estrangeira para enriquecer a nossa, em alguns pontos até mais avançada no que concerne a inovações deliberativas no processo legislativo. 


\section{REFERÊNCIA}

ALVAREZ, Michael R.; HALL, Trad E. Eletronic Elections: the perils and promises of digital democracy. Princeton: Princeton University Press, 2008.

ALVAREZ, Michael R.; HALL, Trad E.; TRECHSEL, Alexander. Internet Voting in Comparative Perspective: The Case of Estonia. Political Science and Politics. Cambridge: Cambridge University Press, v. 42, p. 497-505, 2009.

BEÇAK, Rubens. Democracia: hegemonia e aperfeiçoamento. São Paulo: Saraiva, 2014.

BULOS, Uadi Lâmego. Curso de direito constitucional. 8. ed. rev. e atual. 11. de acordo com a E.C. n. 76/2013. São Paulo: Saraiva, 2014.

CASTANHO, Maria Augusta Ferreira da Silva. O processo eleitoral. (TESE) São Paulo: Universidade de São Paulo, 2014. Orientador(a): Mônica Hermann Salem Caggiano.

FERREIRA FILHO, Manoel Gonçalves. Do processo legislativo. 7. ed. rev. e atual. São Paulo: Saraiva, 2012.

GUTMANN, Amy; THOMPSON, Dennis. Why Deliberative Democracy? Princeton: Princeton University Press, 2009.

KEANE, John. The life and death of Democracy. New York: Simon \& Schuster, 2009.

KOK, Alexander. Icelandic National Forum 2010. 2011. Participedia. Disponível em: http://participedia.net/en/cases/icelandic-national-forum-2010. Acesso em: 10 ago. 2015.

LANDEMORE, Helène. Democratic reason : politics, collective intelligence, and the rule of the many. Princeton: Princeton University Press, 2013.

LANDEMORE, Helène. Inclusive Constitution-Making: the Icelandic Experiment. No prelo. p. 6. Disponível em: https://www.academia.edu/5289629/Inclusive_ConstitutionMaking_the_Icelandic_Experiment. Acesso em 10 ago. 2015.

LIJPHART, Arend. Patterns of democracy. New Heaven: Yale University Press, 1999.

MORLINO, Leonardo. Democracias y democratizaciones. Trad. Cesar Cansino y Israel Covarrubias. CEPCOM: Mexico, 2005.

OLIVEIRA, Bruno Batista da Costa de. A participação popular no processo legislativo: o exercício da cidadania ativa e o discurso do Estado democrático de direito no Brasil. 2010. Dissertação (Mestrado em Direito do Estado) - Faculdade de Direito, Universidade de São Paulo, São Paulo, 2010. 
PATEMAN, Carole. Participação e teoria democrática. Trad. Luiz Paulo Rouanet. Rio de Janeiro: Paz e Terra, 1992.

SHAPIRO, Ian. The real world of democratic theory. Princeton: Princeton Univesity Press, 2010. 